\title{
Effectiveness of a chemical herder in association with in-situ burning of oil spills in ice-infested water
}

van Gelderen, Laurens; Fritt-Rasmussen, Janne; Jomaas, Grunde

Published in:

Marine Pollution Bulletin

Link to article, DOI:

10.1016/j.marpolbul.2016.12.036

Publication date:

2017

Document Version

Peer reviewed version

Link back to DTU Orbit

Citation (APA):

van Gelderen, L., Fritt-Rasmussen, J., \& Jomaas, G. (2017). Effectiveness of a chemical herder in association with in-situ burning of oil spills in ice-infested water. Marine Pollution Bulletin, 115, 345-351.

https://doi.org/10.1016/j.marpolbul.2016.12.036

\section{General rights}

Copyright and moral rights for the publications made accessible in the public portal are retained by the authors and/or other copyright owners and it is a condition of accessing publications that users recognise and abide by the legal requirements associated with these rights.

- Users may download and print one copy of any publication from the public portal for the purpose of private study or research.

- You may not further distribute the material or use it for any profit-making activity or commercial gain

- You may freely distribute the URL identifying the publication in the public portal 


\title{
Effectiveness of a chemical herder in association with in-situ burning of oil spills in ice-infested water
}

\author{
Laurens van Gelderen ${ }^{a, *}$, Janne Fritt-Rasmussen ${ }^{b}$, Grunde Jomaas $^{a}$ \\ ${ }^{a}$ Department of Civil Engineering, Technical University of Denmark, 2800 Kgs. Lyngby, Denmark \\ ${ }^{b}$ Department of Bioscience, Aarhus University, 4000 Roskilde, Denmark \\ *Corresponding author: lauge@byg.dtu.dk
}

\begin{abstract}
The average herded slick thickness, surface distribution and burning efficiency of a light crude oil were studied in ice-infested water to determine the effectiveness of a chemical herder in facilitating the in-situ burning of oil. Experiments were performed in a small scale $\left(1.0 \mathrm{~m}^{2}\right)$ and an intermediate scale $\left(19 \mathrm{~m}^{2}\right)$ setup with open water and 3/10, 5/10 and 7/10 brash ice coverages. The herded slick thicknesses $(3-8 \mathrm{~mm})$ were ignitable in each experiment. The presence of ice caused fracturing of the oil during the herding process, which reduced the size of the herded slicks and, as a consequence, their ignitability, which in turn decreased the burning efficiency. Burning efficiencies relative to the ignited fraction of the oil were in the expected range (42-86\%). This shows that the herder will be an effective tool for in-situ burning of oil when the ignitability issues due to fracturing of the oil are resolved.
\end{abstract}

Keywords: chemical herder, oil spills, ice-infested water, in-situ burning 


\section{Introduction}

One of the oil spill response methods associated with oil spill preparedness in the Arctic environment is in-situ burning, i.e. burning the oil from the water surface $[1,2]$. In-situ burning is suitable for the Arctic as it can be used in ice-infested waters and it can remove up to $99 \%$ of the oil from the water surface $[3,4]$. In principal, insitu burning can be applied to oil slicks on water of any oil type and slick size as long as the oil can be ignited, which is the main difficulty when using this response method.

In order to ignite the oil, the slick must be at least 1-2 $\mathrm{mm}$ thick to accommodate heat losses to the underlying water $[5,6]$, in addition to other ignition requirements caused by, for example, the oil type weathering state [7]. Since oil spreads out on open water to thicknesses well below $0.1 \mathrm{~mm}$ [1], mechanical or chemical measures are required to gather the oil and thereby increase the slick thickness.

Conventionally, fire-resistant booms have been used to collect and thicken spilled oil on open water $[5,8]$. However, booms are less effective in ice-infested waters [8,9] and are heavy and difficult to handle [10]. An alternative tool is a "herder", a chemical surfactant that spreads out rapidly over a water surface. The primary characteristic of a herder is a high spreading pressure, making it energetically preferable for the herder instead of the oil to occupy the water-air interface [11]. When applied around an oil slick, the herder will 'push' the oil slick into a smaller surface area. As the surface area decreases, the slick thickness of the oil must increase. Herders have been shown to achieve post-herding thicknesses of 3-8 $\mathrm{mm}$ [12], which are sufficient for ignition.

Herders are of particular interest in water with a medium (3/10-7/10) ice coverage because fire booms have only been effectively used in ice coverages up to 3/10 [3] and the ice inhibits the spreading of the oil above a $7 / 10$ ice coverage $[13,14]$. Experiments have shown that herders could effectively increase the slick thickness in this range of ice coverages (3/10-7/10) [12]. Crude oil has also been successfully herded under swell wave conditions [15], on open sea [16] and in cold temperatures $\left(-21\right.$ to $\left.0^{\circ} \mathrm{C}\right)$ [12] and herded oil slicks could reach burning efficiencies up to $94 \%$ of the oil $[12,16]$. During the herding of oil in ice-infested waters, however, oil

slicks were observed to break up into multiple slicks after the herder had been applied [12]. This fracturing of the oil slick would inhibit flame spreading, since flames cannot spread between separate oil slicks.

There is currently very little knowledge on how the formation of multiple oil slicks would influence in-situ burning and the achieved burning efficiency, here defined as the wt\% of oil removed from the water surface. Previous studies reporting the fracturing of herded oil slicks focused on the herded slick thickness and did not study the in-situ burning of these fractured slicks [12]. Considering that one of the main uses of herders is to facilitate in-situ burning, the burning efficiency should not be reduced by fracturing of the oil slick during the herding process.

Fracturing of an oil slick may be due to the presence of ice on the water surface, since the formation of multiple slicks has not been observed in open waters under similar calm weather conditions [15]. It is therefore important to map the effects of ice on the herding process in order to determine the ice conditions under which herders can effectively facilitate in-situ burning of oil. In this study the pre- and post-herding slick thickness, surface distribution and burning efficiency of a crude oil on ice-infested water were studied as a 
function of the ice coverage. Herding of oil in ice-infested water was studied in both small and intermediate scale experiments to investigate whether the results can be extrapolated to full scale scenarios.

\section{Materials and methods}

The experimental herder application procedure was designed to create semi-realistic testing conditions. Experiments were conducted in a small scale laboratory setup $\left(1.0 \mathrm{~m}^{2} \times 0.5 \mathrm{~m}\right.$ (water depth) square water basin) and in an outdoor intermediate scale setup $\left(19 \mathrm{~m}^{2} \times 1.0 \mathrm{~m}\right.$ (water depth) octagonal water basin) (Figure 1). The water basins were filled with fresh water and artificially made brash ice (ice fragments $<2 \mathrm{~m}$ in length [17]) was used to create ice coverages of $3 / 10,5 / 10$ and $7 / 10$. The boundaries of the water basins should be considered as large ice floes, between which the oil could spread. DUC crude oil ( $\rho=0.85 \mathrm{~g} / \mathrm{ml}, \eta=6.75 \mathrm{mPa} \cdot \mathrm{s})$, a light blend crude oil from the North Sea, was used in all experiments. The amount of oil used $\left(200 \mathrm{~g} / \mathrm{m}^{2}\right.$ of open water surface) was inversely proportional to the ice coverage in order to maintain the same open water surface area-to-oil ratio and achieve a similar spread thickness in each experiment. The herder used in this study, Siltech OP-40 (previously known as Silsurf A004-UP [18]), has been shown to sufficiently thicken crude oils in fresh and salt water for in-situ burning purposes $(\geq 2 \mathrm{~mm}$ ) [15]. Because the herder performed better in salt water, the use of fresh water was considered to be the more conservative option.
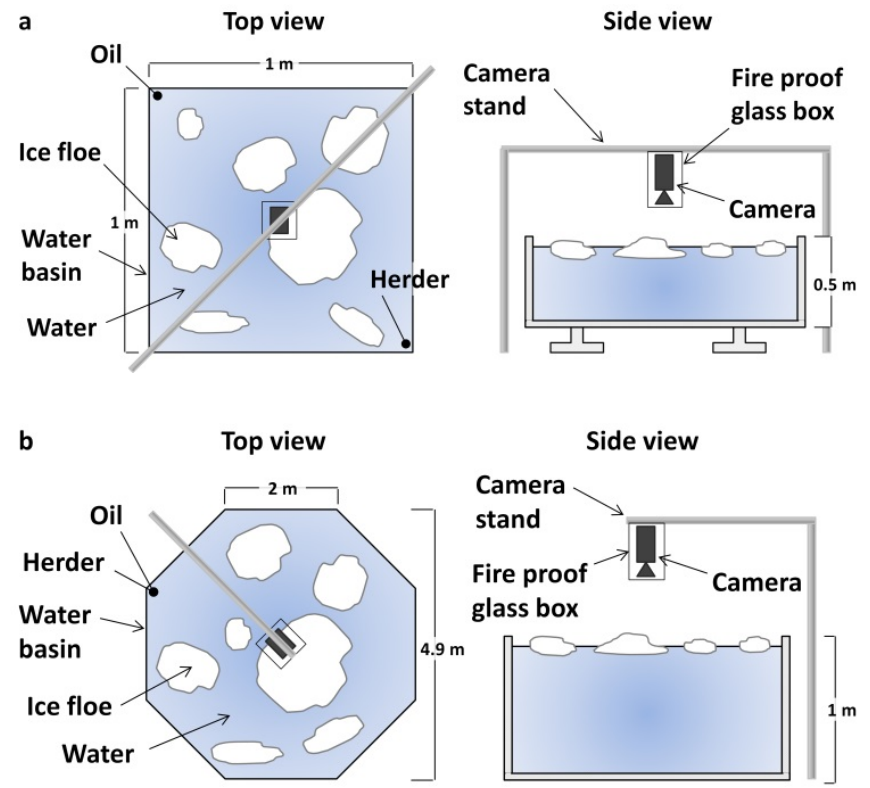

Figure 1. Experimental setup for the small scale (a) and intermediate scale (b) experiments. Small scale experiments were conducted indoor and intermediate scale experiments were conducted outdoor. The "oil" and "herder" labels indicate the location in the basin where these products were applied on the water surface. 
In a typical experiment, the DUC crude oil was poured slowly on the water surface from a corner of the basin and was allowed to spread for $30 \mathrm{~min}$. The herder (Siltech OP-40) was then applied in a single corner of the basin, simulating the herding of oil at the edge of the spill towards its center (Figure 2). After $30 \mathrm{~min}$, the herded oil was ignited one slick at a time and allowed to burn until extinction. The burn residues were collected with $3 \mathrm{M}$ hydrophobic absorption pads, were then dried overnight in an oven at $50^{\circ} \mathrm{C}$ and weighed afterwards to determine the burning efficiency. A digital camera was used to monitor the experiment from above. Images were taken every 10 seconds to measure the surface area and surface distribution of the crude oil.

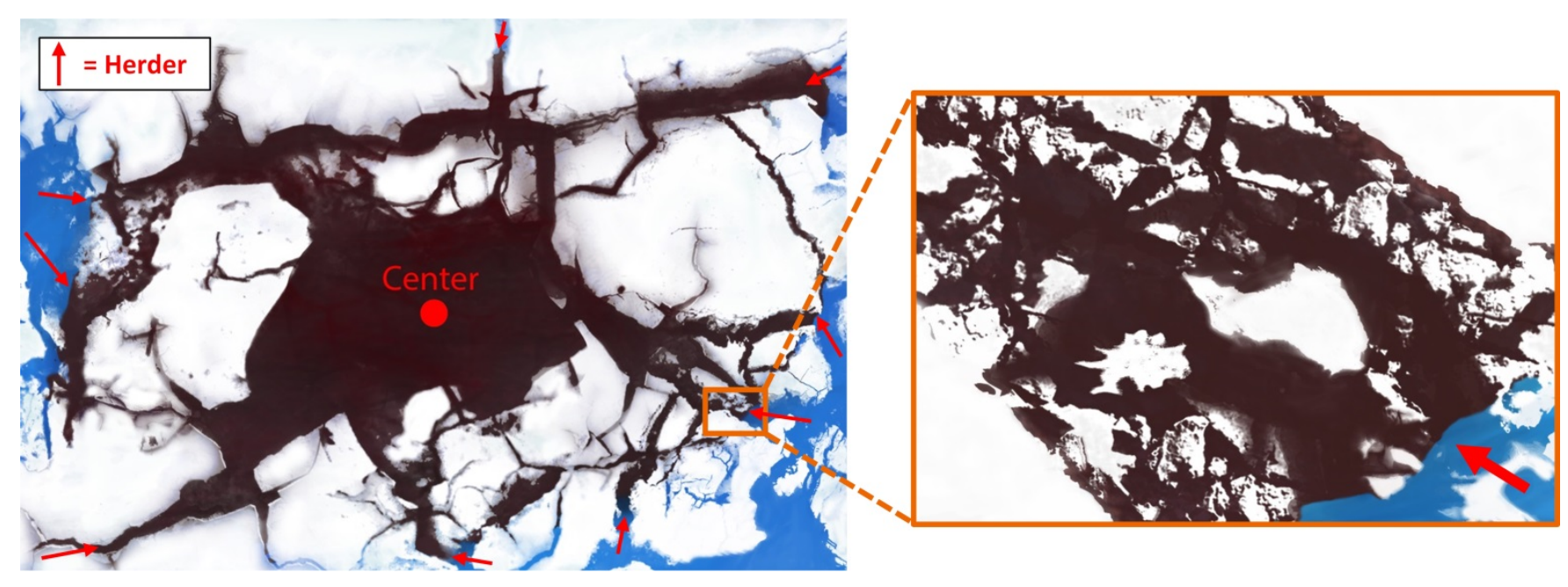

Figure 2. Sketches of a full scale oil spill scenario (left) and close-up of the edge of the oil slick (right), annotated by the orange rectangle and simulated in the experiments.

The experimental conditions of the small scale and intermediate scale experiments are summarized in Table 1 and their procedural details are described below. For the small scale experiments (indoors), the artificial brash ice was 3-5 $\mathrm{cm}$ thick and made from fresh water. The herder $\left(50 \mu \mathrm{L} / \mathrm{m}^{2}\right.$ water) was applied in the corner opposite of the original spreading location of the oil (see Figure 1a) and ignition of the oil slicks was attempted with a butane hand torch. The basin was thoroughly cleaned with a hot water solution of Alconox detergent powder $(10 \mathrm{~g} / \mathrm{L})$, before and after each experiment, to remove the herder from the steel walls. Surface tension measurements of the water prior to applying the ice and oil were in the expected range $(68-71 \mathrm{mN} / \mathrm{m})$ and confirmed that the herder had been removed successfully. Each of the small scale experiments was conducted twice.

For the intermediate scale experiments (outdoors) the oil was applied in an upwind corner to ensure the oil would spread over the water surface. The wind had a significant influence on the spreading and herding behavior of the oil, which caused some repeatability issues and hence the experiments are shown individually in Table 1. Nevertheless, these issues were, after thorough analysis, not seen to alter the main outcome of the study. The recommended operational herder dose of $150 \mu \mathrm{L} /\left(\mathrm{m}^{2}\right.$ water surface) was used to overcome the 
effects of the wind [19]. The herder was applied in the same upwind corner as the oil so that the wind would not inhibit the herding process (see Figure $1 \mathrm{~b}$ ). Local wind speeds were measured on site using a wind speed meter (see Table 1). The brash ice in these experiments was made in $80 \times 50 \times 30 \mathrm{~cm}^{3}$ casts in a $-20{ }^{\circ} \mathrm{C}$ freezer. Initial ice coverages of 3/10 were prepared, but due to melting of the ice during the preparation of the experiments with ice the actual ice coverages tested were $2 / 10$ and 2.5/10. Ignition of the oil slicks was attempted with either a weed burner or a burner and 3-50 $\mathrm{ml}$ ignition gel (8:2:0.1 mixture of diesel, gasoline and G-760 gelling agent) that was poured and ignited on a central location of an oil slick. Surface tension measurements of the water $(70-71 \mathrm{mN} / \mathrm{m})$ prior to applying the ice and oil showed that there was no significant herder residue left in the basin in between experiments.

\begin{tabular}{|c|c|c|c|c|c|c|c|}
\hline $\begin{array}{l}\text { Experimental } \\
\text { scale }\end{array}$ & $\begin{array}{c}\text { Water } \\
\text { surface } \\
\text { area }\left(m^{2}\right)\end{array}$ & $\begin{array}{c}\text { Ice } \\
\text { coverage }\end{array}$ & $\begin{array}{c}\text { Oil } \\
\text { amount } \\
\text { (g) }\end{array}$ & $\begin{array}{l}\text { Herder } \\
\text { amount } \\
(\mu L)\end{array}$ & $\begin{array}{l}\text { Ice fragment } \\
\text { diameter }(\mathrm{cm})\end{array}$ & $\begin{array}{c}\text { Water } \\
\text { temperature } \\
\left({ }^{\circ} \mathrm{C}\right)^{b}\end{array}$ & $\begin{array}{l}\text { Wind } \\
\text { speed } \\
(\mathrm{m} / \mathrm{s})^{c}\end{array}$ \\
\hline Small & 1 & No ice & 200 & 50 & - & 5.4 & - \\
\hline Small & 1 & $3 / 10$ & 140 & 50 & $10-30$ & 8.2 & - \\
\hline Small & 1 & $5 / 10$ & 100 & 50 & $10-30$ & 8.1 & - \\
\hline Small & 1 & $7 / 10$ & 60 & 50 & $10-30$ & 3.3 & - \\
\hline Intermediate & 19 & No ice & 3780 & 2835 & - & 7.4 & $3-4$ \\
\hline Intermediate & 19 & No ice & 3780 & 2835 & - & 8.8 & $3-4$ \\
\hline Intermediate & 19 & $2.5 / 10^{\mathrm{a}}$ & 2646 & 2835 & $40-75$ & 6.1 & $<2$ \\
\hline Intermediate & 19 & $2 / 10^{\mathrm{a}}$ & 2646 & 2835 & $40-75$ & 7.2 & $3-6$ \\
\hline $15 \mathrm{~L}$ experiment & 19 & No ice & 12795 & 4935 & - & 14.3 & $<2$ \\
\hline
\end{tabular}

The ignition of a larger volume of free-floating herded oil $(15 \mathrm{~L})$ was also tested in the intermediate scale setup. During this experiment, the herder was applied in six doses of $473 \mu \mathrm{L}$ of herder around the oil slick. After thirty minutes of herding, the oil slicks were adjacent to the basin boundaries and an additional $2100 \mu \mathrm{L}$ was applied around the oil slicks to force the oil slicks onto the open water surface prior to ignition. The oil slicks were each ignited with approximately $50 \mathrm{ml}$ of ignition gel and a weed burner.

The camera images were analyzed in Photoshop CC 2015 using color sensitive selection tools to select the preand post-herding oil slicks on the water surface. These tools were chosen over manual selection of the oil slicks to eliminate subjective bias. Pixel measurements of the oil slicks indicated the number of individual areas and were compared to the pixel area of the water basin to calculate the slick areas in $\mathrm{m}^{2}$. Based on the initial oil volume (the weight of the oil divided by the density of the oil) and assuming a uniform thickness distribution, the average slick thickness of the oil could then be calculated [12]. 


\section{Results and discussion}

\subsection{Slick thickness}

The average slick thicknesses after 30 minutes of spreading and subsequently 30 minutes of herding are shown in Figure 3 as a function of the ice coverage. The data show that the spread oil slicks were in general not ignitable, as the majority of the spread thicknesses in all ice coverages was well below the theoretical ignitability limit of 1-2 mm [5]. Although two of the intermediate scale experiments showed thicker spread thicknesses (1-2 mm), the causes were not related to the presence of ice. The spread thickness of the $15 \mathrm{~L}$ experiment was about 3-4 times larger $(1 \mathrm{~mm})$ than the other experiments without ice, which was expected as its oil-to-water surface ratio was 3.4 times larger. The high spread thickness of $2 \mathrm{~mm}$ for the experiment with a $2 / 10$ ice coverage was caused by strong wind gusts from a single direction that pushed the oil and ice to the opposite side of the basin. As a result, the oil and ice were contained in a small area of the basin for most of the 30 min spreading period. The results thus show that none of the tested ice coverages significantly inhibited the spreading of the oil, which corresponds with previous work [13, 14], and thickening of the oil prior to in-situ burning was indeed required.

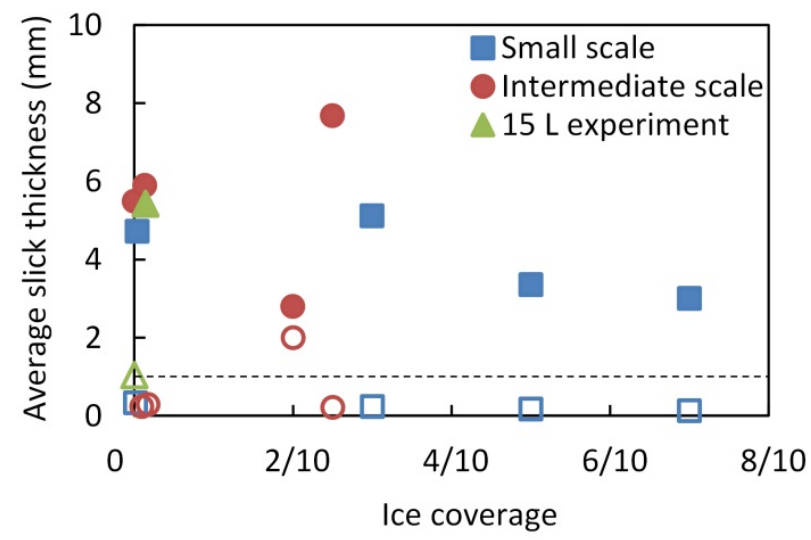

Figure 3. Average slick thickness after 30 minutes of spreading (open symbols) and 30 minutes of herding (closed symbols) as a function of the ice coverage. Data points of experiments with no ice coverage ( 0 on the $x$-axis) are jittered for clarity reasons. The dashed line indicates the theoretical minimal thickness required for ignition $(1 \mathrm{~mm})$.

In all experiments, applying herder to the water surface increased the oil slick thickness to a thickness of 3-8 $\mathrm{mm}$ (Figure 3). The herded slick thicknesses were all theoretically ignitable, independent of the ice coverage, and were thus sufficiently thickened to apply in-situ burning. These results match well with earlier results on herded oil thicknesses in ice-infested water [12]. 
Increasing the ice coverage resulted in a maximum herded slick thickness around an ice coverage of 3/10, after which the herded slick thickness decreased for higher ice coverages. The low herded slick thickness of the 2/10 ice coverage experiment compared to the other intermediate scale experiments was attributed to the slick already being pre-herded by the wind into a small area. As a consequence, most of the oil was effectively shielded from the thickening effect of the herder by a barrier of ice and pre-thickened oil. The maximum herded slick thickness for a 3/10 ice coverage was also observed in previous experiments on herding oil in icecovered water [16]. This correlation suggests that the ice has two competing effects on the herding process. A possible explanation is that a $3 / 10$ ice coverage provides additional boundaries against which the oil can be herded, while the ice concentration is not yet so high that it physically obstructs the herder. For the purposes of this study, however, the thickness reducing effect of high ice coverages (5/10-7/10) was not considered relevant because all herded thickness were theoretically ignitable. Overall, the slick thickness results corresponded well with results from literature $[12,16]$, both in absolute values and as a function of the ice coverage. The experiments provided therefore suitable circumstances to study how the theoretical ignitable thickness would translate to the actual ignitability of these herded slicks in ice-infested water.

\subsection{Herded oil slick distribution}

Although the final herded slick thickness was not significantly affected by the presence of ice, the ice had a clear influence on the herding process. An impression of the oil-ice-herder interactions during the herding process is given in Figure 4. The herder spread considerably slower over the water surface in experiments with a high ice coverage. Ice blocks physically blocked the herder and this caused the herder front to spread asymmetrically over the water surface. Any oil that was hindered in its movement as it was stuck on, between or adjacent to ice fragments was unable to follow the herder front and became separated from the rest of the oil. Once a fraction of the oil slick was fully surrounded by herder, it would not easily merge with other oil fragments and alternatively form a new slick or droplet. This interaction between the asymmetrically advancing herder front and slowed or trapped oil caused the oil to fracture into tens to hundreds of such separate oil slicks and droplets. 


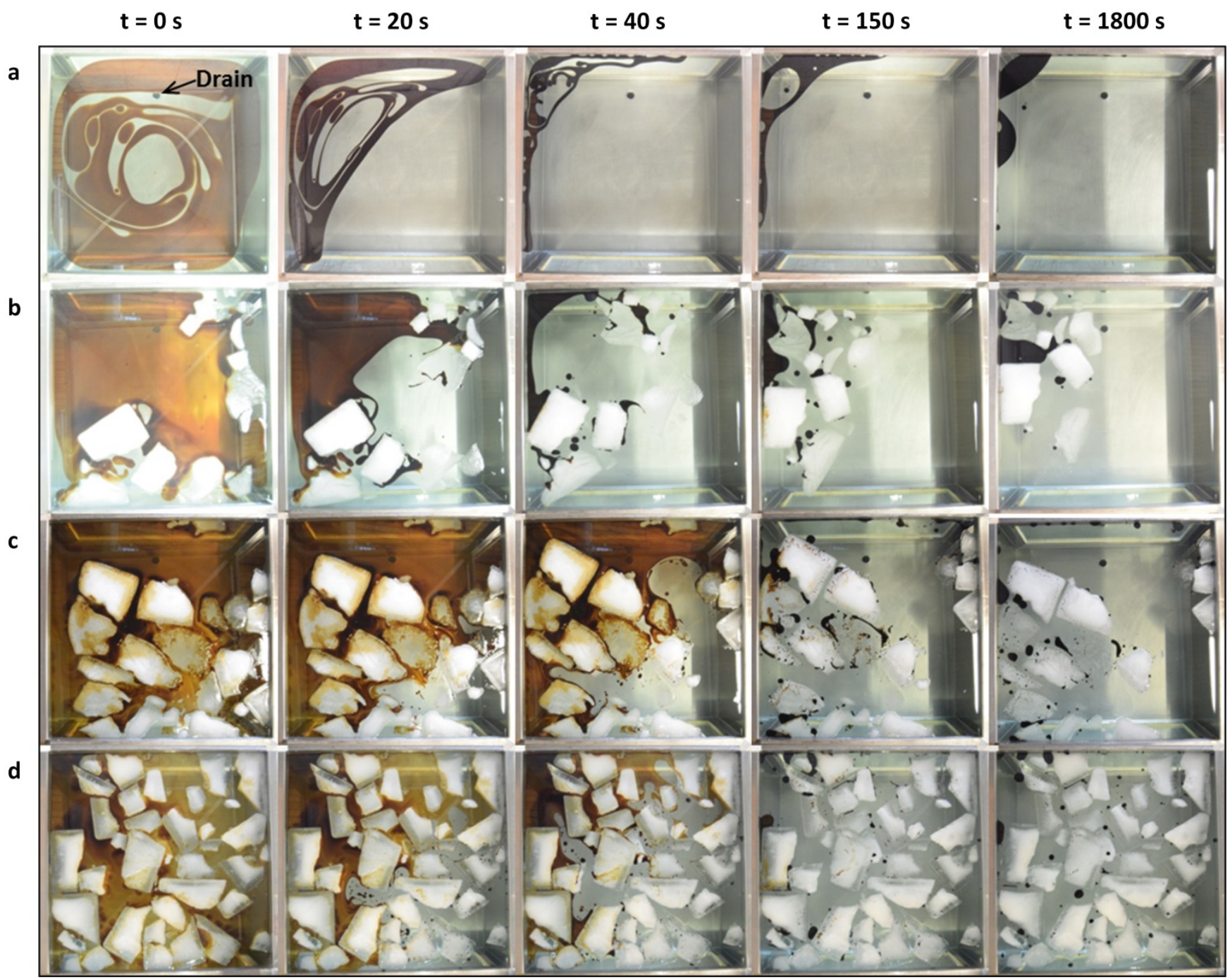

Figure 4. Snapshots of the herding process of the crude oil in an experiment without ice (a) and an ice coverage of $3 / 10$ (b), 5/10 (c) and $7 / 10$ (d). The first picture in each row shows the oil slick right before the herder was applied. The herder front can be observed from the border between the retracting oil surface and the water surface.

The surface distribution of the herded oil slicks after $30 \mathrm{~min}$ of herding is shown in Figure 5 . Because the surface distribution of the oil was unique for each experiment, the data sets are shown individually. The total number of oil slicks and droplets and the relative size of the largest oil slick are also summarized in Table 2. Each data point in Figure 5 resembles an individual oil slick and the data points are in order of increasing slick size. In this study an individual oil slick or droplet was defined as any amount of oil surrounded completely by water, ice or the boundaries of the water basin. The relative size of a specific oil slick or droplet can be derived from the difference between its value on the $y$-axis and the value of the point below it. For example, the second $3 / 10$ ice data set consists of 9 slicks, with the largest slick occupying $37 \%$ of the total surface area. Thin oil sheens that had spread on the ice typically formed several hundred oil droplets during the herding process 
that greatly increased the total number of slicks and droplets, but occupied only a very small area. Including all these droplets in the surface distribution analysis would misrepresent the extent of the fracturing of the oil slick in terms of in-situ burning purposes. Therefore, the smallest oil droplets accounting for a cumulative $5 \%$ of the total area were omitted from Figure 5 and Table 2.

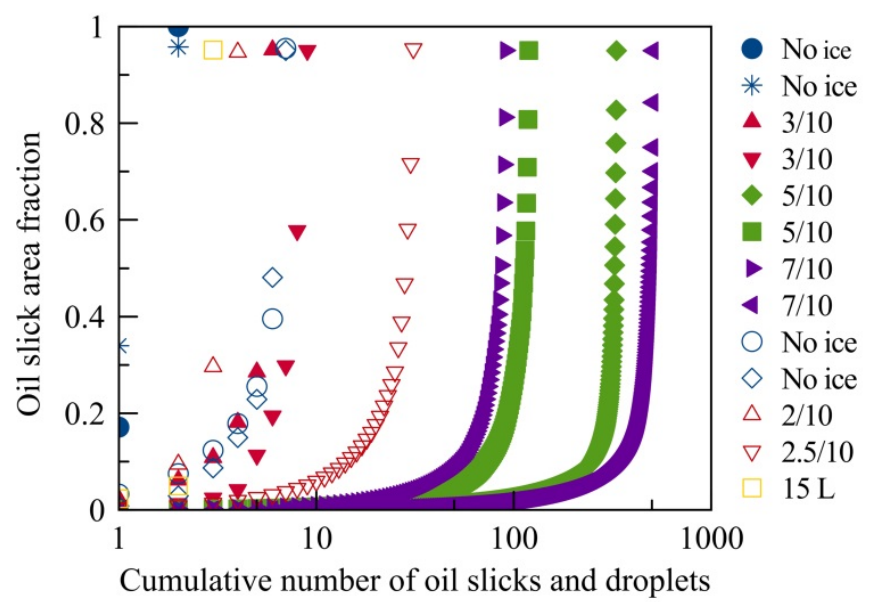

Figure 5. Surface distribution of the herded oil slicks after $30 \mathrm{~min}$ of herding in small scale experiments (closed symbols) and intermediate scale experiments (open symbols).

\begin{tabular}{lccc}
\hline \multicolumn{4}{c}{ Table 2. Summary of herded oil slick distribution } \\
\hline Scale & $\begin{array}{c}\text { Ice } \\
\text { coverage } \\
\text { No ice }\end{array}$ & $\begin{array}{c}\text { Slicks } \\
\text { (\#) }\end{array}$ & $\begin{array}{c}\text { Largest slick } \\
\text { (oil area \%) }\end{array}$ \\
Small & No ice & 2 & 83 \\
Small & $3 / 10$ & 6 & 96 \\
Small & $3 / 10$ & 9 & 67 \\
Small & $5 / 10$ & 331 & 37 \\
Small & $5 / 10$ & 119 & 12 \\
Small & $7 / 10$ & 91 & 14 \\
Small & $7 / 10$ & 506 & 11 \\
Small & No ice & 7 & 56 \\
Intermediate & No ice & 7 & 47 \\
Intermediate & $2.5 / 10$ & 31 & 24 \\
Intermediate & $2 / 10$ & $4^{\text {a }}$ & 65 \\
Intermediate & No ice & 3 & 90 \\
15 L experiment & a & Increased coherency due to wind, see also Section 3.1. \\
\hline \multicolumn{4}{l}{} \\
\hline
\end{tabular}


The oil slick distribution data show a clear increase in the extent of the fracturing of the herded oil slick as a function of the ice coverage (Figure 5). A higher ice coverage increased the number of oil slicks and droplets and reduced the (relative) size of the largest oil slick post-herding in both experimental scales. While the precise distribution and size of the oil slicks could not simply be derived from the ice coverage alone, it was clear from the results that the ice prevented the oil from being herded into a single slick. These results correspond with previous herding experiments of crude oil in ice-infested water [12].

Fracturing of the oil slick has also been observed in a large scale experiment featuring the herding of $630 \mathrm{~L}$ of crude oil on open sea, which resulted in three oil slicks prior to ignition [21]. This shows that large oil slicks are also susceptible to fracturing, of which the extent would further increase in the presence of ice. Slicks were larger in size and more fractured in the intermediate scale than in the small scale experiments for similar ice coverages. The results also show that the more the oil comes into contact with ice, the higher the extent of the fracturing of the oil becomes. Extrapolating these results to operational scales suggests that herding a large oil slick in ice-infested water would result in a large amount of big oil slicks scattered all over the area occupied by the ice (such as in Figure 4). The implications of such a large, fractured oil slick are discussed in the next section.

\subsection{Ignition of herded oil}

Ignition of the herded oil was attempted on several slicks per experiment and resulted in the successful ignition of and flame spread on at least one slick in each experiment. This confirms that all average herded slick thicknesses (Figure 3) were thick enough for in-situ burning and shows that the herder is capable of facilitating this response method in ice-infested waters. Fracturing of oil slicks, as described above, however, considerably complicated and inhibited the ignition procedure. The slick thickness alone was thus not a sufficient measurement to determine the full extent of the ignitability of the herded oil.

Monitoring which oil slicks had been burned and which remained unburned was challenging because slicks were in motion during the burning and occasionally burning slicks would merge with other slicks. Igniting slicks separately was also more labor intensive and combined with the large area that could be occupied by large herded slicks, fracturing of an oil slick in operational scales could create a dilemma. Either the logistics become more complex when trying to ignite all oil slicks, whereas simple logistics is normally a selling point for in-situ burning [5], or some (small) slicks are neglected but this reduces the burning efficiency. This dilemma would in particular be present when herding oil in ice-infested waters and thorough preparations should be in place for in-situ burning operations in such scenarios.

Successful ignition of an oil slick mainly depended on the size of an oil slick and its immediate surroundings. For the small scale experiments, all slicks with a diameter $\geq 5 \mathrm{~cm}$ could be ignited. Smaller slicks probably lost too much heat to the surrounding water to sustain a fire. Ignition was much harder for the intermediate scale experiments, partially due to the influence of the wind. Typically, oil slicks that were not adjacent to either ice blocks or the boundaries of the basin could not be ignited for the experiments with $200 \mathrm{~g}$ oil $/ \mathrm{m}^{2}$ of water. Ignition attempts with a weed burner and ignition gel $(5-10 \mathrm{ml})$ failed to ignite free-floating slicks with areas of 
$\leq 0.45 \mathrm{~m}^{2}$ and $\leq 0.20 \mathrm{~m}^{2}$, respectively. The small ignition sources were not strong enough to overcome the blowout effects of the wind. Adding larger amounts of ignition gel (up to $50 \mathrm{ml}$ ) did not aid the ignition of these free-floating slicks as the ignited gel displaced the oil slick rather than spreading on top of the oil to spread the flames. Observations during the experiments gave the impression that the oil slicks were too small to maintain their coherency under the spreading pressure of such higher amounts of ignition gel. This theory was successfully tested during the experiment with $15 \mathrm{~L}$ of oil in which a free-floating slick of $1.9 \mathrm{~m}^{2}$ was burned, starting from an ignition gel $( \pm 50 \mathrm{ml})$ fire of $0.2 \mathrm{~m}^{2}$.

Herded slicks adjacent to ice blocks or basin boundaries were more shielded from the wind and not as easily displaced and were therefore easier to ignite. Contrary to free-floating slicks, such confined slicks could be ignited with just the weed burner or small amounts of gel $(5-10 \mathrm{ml})$, although ignition was not always successful either. Larger amounts of ignition gel were also tested for confined slicks that otherwise failed to ignite, but because of their small slick size $\left(<0.25 \mathrm{~m}^{2}\right)$ the ignition gel would only displace the slicks and not spread the flames on the oil. This shows again that small slicks, their small size a consequence of the fracturing of the oil slick, were very difficult or failed to ignite. As a consequence, the success rate of the ignition attempts for the intermediate scale experiments was low $(<50 \%)$ and only in the $15 \mathrm{~L}$ experiment $96 \%$ of the oil was set on fire, compared to $11-57 \%$ for the other experiments. Because any unburned oil is treated as residue during cleanup after in-situ burning, failure to ignite a fraction of the oil reduces the burning efficiency. Fracturing of a herded oil slick can therefore reduce the burning efficiency by forming (small) oil slicks that are no longer ignitable due to their reduced size.

The ice blocks used in the experiments are representative for the smaller pieces of brash ice and pancake ice that can be observed on sea in ice conditions such as open ice and around larger ice floes [17]. Formation of small, non-ignitable slicks in these types of ice-infested water for operational scales should therefore be considered as a possibility. The herded oil slick distribution in the intermediate scale experiments (Figure 5) showed that the formation of very small droplets $(<5 \mathrm{~cm}$ in diameter) is negligible in larger scales than the small scale experiments. On sea, smaller pieces of brash ice are thus more probable to form slicks with an area of about $0.1-0.5 \mathrm{~m}^{2}$ that contain a notable amount of oil but are still difficult to ignite, similar to the intermediate scale results.

\subsection{Burning efficiency}

The burning efficiency of the herded oil slicks is shown in Figure 6 as a function of the ice coverage. Correlating the burning efficiency to the herded slick thickness showed that the burning efficiency was independent of the thickness of the burned slicks. The herded slick thickness (Figure 3) was therefore only relevant for the ignitability of the oil, which has also been proposed in a previous study [20]. All trends observed in the burning efficiency data could be explained by the scale of the experiment, the presence of ice and the surface distribution of the oil, as discussed below. 


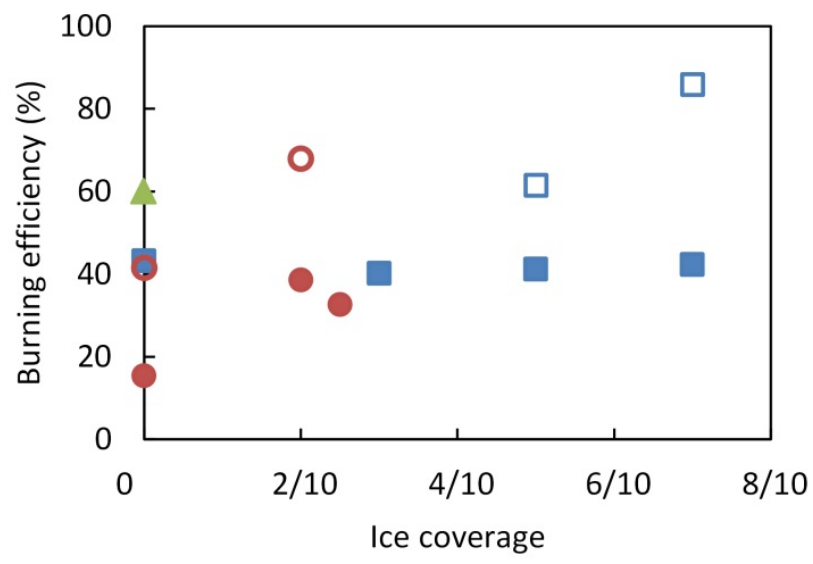

Small Scale O Intermediate scale $\Delta 15 \mathrm{~L}$ experiment

Figure 6. Burning efficiency of herded oil slicks as a function of the ice coverage. Closed symbols show the absolute burning efficiency, which is based on the initial oil weight and the total weight of the residue (burned and unburned). Open symbols show the effective burning efficiency, which is the absolute burning efficiency relative to the oil area fraction that was set on fire (i.e. burned residue).

For the small scale experiments, the obtained burning efficiencies were independent of the ice coverage. However, due to the fracturing of the oil, $31-56 \%$ of the total oil surface area could not be ignited during the experiments with a 5/10 and 7/10 ice coverage. By dividing the burning efficiency with the area fraction of the oil that was set on fire, the burning efficiency of only the burned oil fraction was obtained, i.e. the effective burning efficiency. The effective burning efficiency should be used as an estimate of the potential burning efficiency if all oil could have been ignited and set on fire, rather than as an exact result. For example, the effective burning efficiency was very high for the $7 / 10$ ice coverage experiments (86\%) and based on the amount of residue observed in these experiments was likely overestimated. It does, however, give a clear indication that the burning efficiency would increase with increasing ice coverage in the small scale experiments if ignition of small oil slicks would not be an issue.

For the intermediate scale experiments the burning efficiencies were relatively low (15-39\%, see Figure 6), which was mainly caused by ignition issues. Hardly any oil slicks could be ignited in the experiments without ice and only $11-37 \%$ of the oil area was set on fire, resulting even in a negligible burning efficiency for the first of these experiments. The higher burning efficiencies for the 2/10 and 2.5/10 ice coverage experiments were achieved because a higher area fraction could be set on fire, although this fraction was still below $60 \%$. In comparison, $96 \%$ of the oil was set on fire in the $15 \mathrm{~L}$ experiment, resulting in a burning efficiency of $60 \%$. Similar ignition issues have also been observed to decrease the burning efficiency in a study on the burning of herded oil slicks in cold $\left(<0{ }^{\circ} \mathrm{C}\right)$ weather conditions [12]. In such experiments dominated by the ignition process, the effective burning efficiency gives a better estimate of the burning results (Figure 6) and was used for further discussion. No top view photos were made of the ignition and burning of oil in the 2.5/10 ice coverage experiment out of safety concerns and hence the effective burning efficiency could not be calculated for this experiment. 
The effective burning efficiency of the intermediate scale experiment without ice was relatively low compared to the small scale experiments, as larger oil slicks typically have higher burning efficiencies (see Figure 7). The burning efficiency was probably affected by the outdoor conditions such as wind and a light drizzle. Increasing the ice coverage also resulted in an increasing burning efficiency in the intermediate scale (even compared to the $15 \mathrm{~L}$ experiment), which matched the results of the small scale experiments. This increase in burning efficiency with increasing ice coverage could be caused by the ice working as a confinement around the oil, inhibiting the spreading of the oil during the burning. Free-floating herded oil slicks expanded upon ignition so their thickness was reduced faster than herded slicks that could not expand. Heat losses to the water affect expanding slicks sooner, leading to earlier extinction of the flame and could therefore lower burning efficiencies. Thus, when fracturing of herded oil in ice-infested waters does not inhibit ignition, the presence of the ice could in fact aid in-situ burning of the oil.

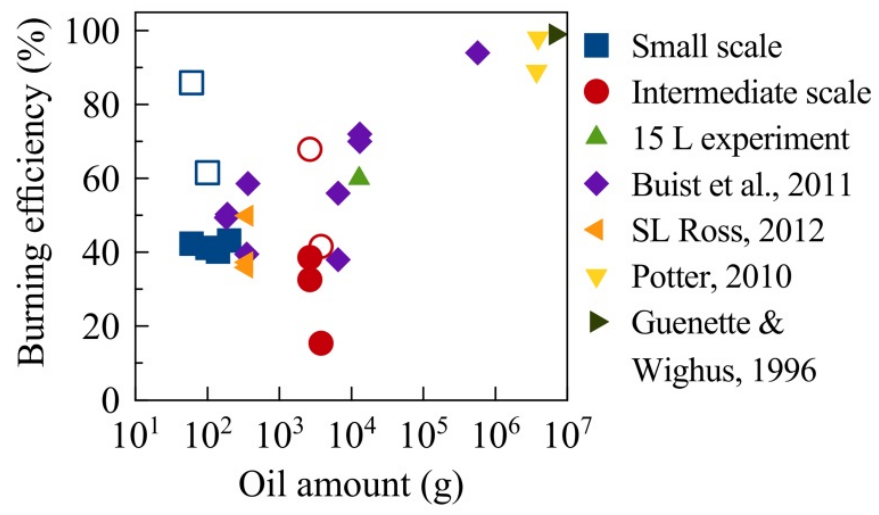

Figure 7. Burning efficiency as a function of the oil amount. Open symbols show the effective burning efficiency, which is relative to the oil area that was set on fire. Literature data was taken from Buist et al. [16], SL Ross [15], Potter [3] and Guénette and Wighus [4].

Plotting the burning efficiencies as a function of the oil mass and comparing the data to burning efficiencies of similar experiments from literature shows that the results are within the expected range for the tested scales (Figure 7). Apart from the ignition issues, the in-situ burning of the herded oil, in both water with and without ice, performed appropriately relative to the experimental scales. These results show that the tested herder can be an effective tool to facilitate in-situ burning in ice-infested waters. The main issue that should be solved to optimize its effectiveness is to ensure ignition of all the oil slicks that result from fracturing of an oil slick during the herding process. This can be achieved either by limiting the fracturing of the oil slick and avoiding the formation of many small and difficult to ignite slicks, or by a strong ignition source that can easily be applied on multiple locations in a large area. Research on an operational scale will be required to determine which of these options is the most realistically achievable. 


\section{Conclusion}

In small and intermediate scale experiments, spread oil slicks were herded in ice-infested waters from thicknesses of 0.1-2 $\mathrm{mm}$ to 3-7 $\mathrm{mm}$, depending on the ice coverage. These herded slick thicknesses were all theoretically ignitable and indeed at least one oil slick per experiment was successfully ignited. Fracturing of the oil during the herding process, however, complicated the ignition process and many of the smaller slicks and droplets formed were non-ignitable, negatively affecting the burning efficiency. This would cause a dilemma on an operational scale as either more complex logistics are required to ignite all the oil, or some fraction of the oil remains unburned which reduces the burning efficiency.

Of the ignited oil slicks, the effective burning efficiency was within the expected range for the small and intermediate scale experiments (42-86\% and $42-68 \%$, respectively). The herder thus successfully facilitated insitu burning of oil in ice-infested water because it herded spread oil to an ignitable thickness and ignited oil resulted in expected burning efficiencies. Ignitability issues of oil slicks, both logistically and the actual ignition, due to fracturing of the oil in ice-infested water should be addressed in order for the herder to become a fully effective tool for the in-situ burning of oil.

\section{Acknowledgements}

The Danish Council for Independent Research provided funding for the project (Grant DDF - 1335-00282). COWIfonden funded the construction of the small scale experimental rig, Maersk Oil provided the crude oil that was used in this study and DESMI provided the chemical herder. None of the sponsors have been involved in the experiments, analysis or conclusions of this paper. The authors would also like to thank Eirini Adamopoulou (M.Sc. student), Marc Martorell (B.Sc. student), Barbara Falatova (Ph.D. student) and Bjørn Skjønning Andersen (research assistant) for their assistance with the intermediate scale experiments and Gunvor Kirkelund (Assoc. Prof.) for reviewing an early draft of this manuscript.

\section{References}

[1] I.A. Buist, S.G. Potter, B.K. Trudel, S.R. Shelnutt, A.H. Walker, D.K. Scholz, P.J. Brandvik, J. Fritt-Rasmussen, A.A. Allen, and P. Smith, In Situ Burning in Ice-Affected Waters: State of Knowledge Report, Final Report 7.1.1, Arctic Response Technology, 2013.

[2] Nuka, Research \& Planning Group, LLC., Oil Spill Prevention and Response in the U.S. Arctic Ocean: Unexamined Risks, Unacceptable Consequences, The PEW Environment Group, Washington, D.C., 2010.

[3] S. Potter, Tests of Fire-Resistant Booms in Low Concentrations of Drift Ice - Field experiments May 2009., Report No. 27, SINTEF, Trondheim, 2010.

[4] C.C. Guénette and R. Wighus, In-Situ Burning of Crude Oil and Emulsions in Broken Ice, Environment Canada (1996), pp. 895-906. 
[5] I. Buist, J. McCourt, S. Potter, S. Ross, and K. Trudel, In Situ Burning, Pure Appl. Chem. 71 (1999), pp. 43-65.

[6] T.A. Brzustowski and E.M. Twardus, A Study of the Burning of a Slick of Crude Oil on Water, Symp. (Int.) Combust. 19 (1982), pp. 847-854.

[7] J. Fritt-Rasmussen, P.J. Brandvik, A. Villumsen, and E.H. Stenby, Comparing Ignitability for In Situ Burning of Oil Spills for an Asphaltenic, a Waxy and a Light Crude Oil as a Function of Weathering Conditions Under Arctic Conditions, Cold Reg. Sci. Technol. 72 (2012), pp. 1-6.

[8] S. Potter, I.A. Buist, B.K. Trudel, D. Dickins, and E. Owens, Spill Response in the Arctic Offshore, American Petroleum Institute, Washington, D.C., 2012.

[9] M. Bronson, E. Thompson, F. McAdams, and J. McHale, Ice Effects on a Barge-Based Oil Spill Response System in the Alaskan Beaufort Sea, Environment Canada (2002), pp. 1253-1267.

[10] S. Potter, Tests of Fire-Resistant Booms in Low Concentrations of Drift Ice - Field experiments May 2008., Report No. 5, SINTEF, Trondheim, 2010.

[11] W.D. Garrett, Confinement And Control Of Oil Pollution On Water With Monomolecular Surface Films, in: International Oil Spill Conference Proceedings, IOSC, (1969), pp. 257-261.

[12] SL Ross, Mid-scale test tank research on using oil herding surfactants to thicken oil slicks in broken ice, Bureau of Safety and Environmental Enforcement, 2007.

[13] P.J. Brandvik, K.R. Sørheim, I. Singsaas, and M. Reed, Short State-of-the-Art Report on Oil Spills in IceInfested Waters, Report No. 1, SINTEF, 2006.

[14] SL Ross, Environmental Research Ltd., and DF Dickings, Associates Ltd.,, Field Research Spills to Investigate the Physical and Chemical Fate of Oil in Pack Ice, Report No. 62, Environmental Studies Research Funds, Ottawa, 1987.

[15] SL Ross, Research on Using Oil Herding Agents for Rapid Response In situ Burning of Oil Slicks on Open Water, BSEE, Washington D.C., 2012.

[16] I. Buist, S. Potter, T. Nedwed, and J. Mullin, Herding surfactants to contract and thicken oil spills in pack ice for in situ burning, Cold Reg. Sci. Technol. 67 (2011), pp. 3-23.

[17] WMO, WMO Sea Ice Nomenclature, World Meteorological Organization, 2014.

[18] P. Lane, P. Newsom, I.A. Buist, T. Nedwed, A. Tidwell, and K. Flagg, Recent Efforts to Develop and Commercialize Oil Herders, Environment Canada (2012), pp. 472-479.

[19] I.A. Buist, D. Cooper, B.K. Trudel, J. Fritt-Rasmussen, S. Wegeberg, K. Gustavson, P. Lassen, W.U. Rojas Alva, G. Jomaas, and L. Zabilansky, Research Investigations into Herder Fate, Effects and Windows-OfOpportunity, Arctic Response Technology, under review, 2016.

[20] L. van Gelderen, N.L. Brogaard, M.X. Sørensen, J. Fritt-Rasmussen, A.S. Rangwala, and G. Jomaas, Importance of the Slick Thickness for Effective In-Situ Burning of Crude Oil, Fire Saf. J. 78 (2015), pp. 19.

[21] I.A. Buist, S. Potter, and S.E. Sørstrøm, Barents Sea Field Test of Herder to Thicken Oil for In situ Burning in Drift Ice, Environment Canada (2010), pp. 725-742. 